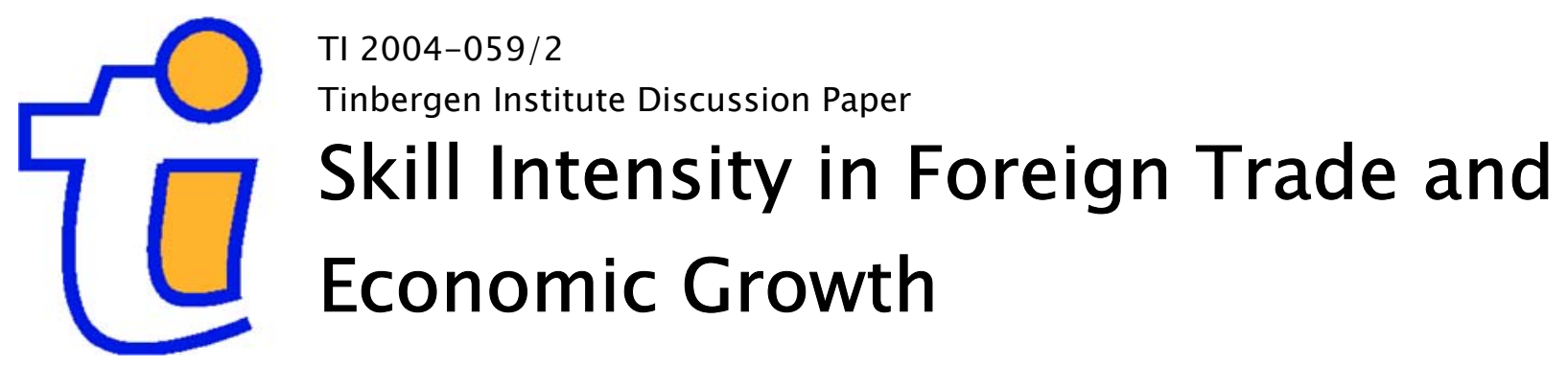

Julia Wörz

Faculty of Economics, Erasmus Universiteit Rotterdam, and Vienna Institute for International Economic Studies (wiiw). 


\section{Tinbergen Institute}

The Tinbergen Institute is the institute for economic research of the Erasmus Universiteit Rotterdam, Universiteit van Amsterdam, and Vrije Universiteit Amsterdam.

Tinbergen Institute Amsterdam

Roetersstraat 31

1018 WB Amsterdam

The Netherlands

Tel.: $\quad+31(0) 205513500$

Fax: $\quad+31(0) 205513555$

Tinbergen Institute Rotterdam

Burg. Oudlaan 50

3062 PA Rotterdam

The Netherlands

Tel.: $\quad+31(0) 104088900$

Fax: $\quad+31(0) 104089031$

Please send questions and/or remarks of nonscientific nature to driessen@tinbergen.nl.

Most TI discussion papers can be downloaded at http://www.tinbergen.nl. 


\title{
Skill Intensity in Foreign Trade and Economic Growth
}

\author{
Julia Wörz* \\ The Vienna Institute for International Economic Studies (wiiw) and Tinbergen Institute
}

\author{
May 2004
}

\begin{abstract}
This paper explores the link between trade structure, trade specialization and per capita income growth. It is argued that industrial upgrading in export specialization patterns has a positive long-run growth effect, while the effect of structural change in industrial import patterns is in principle ambiguous. A standard empirical growth model is augmented by various measures of structural change. The hypothesis that not trade per se matters, but that various types of trading activities impact differently on economic growth is tested on a sample of 45 countries (OECD members and selected Asian and Latin American countries) over the period 1981-1997. The data set comprises exports and imports for 35 manufacturing industries at the 3digit level of the ISIC classification which are grouped according to skill intensity. The results of the dynamic panel estimation point towards a positive long-run growth effect arising from trade specialization in medium-high-skillintensive industries. Further, important distinctions between the skill intensity of export and import patterns and their respective influence on economic development, as well as between the group of developing countries and OECD members are observed in this relationship.
\end{abstract}

Keywords: trade structure, Balassa specialization index, economic growth, spillovers JEL classification: C23, F43, 019, 041, 057

\footnotetext{
* The author is grateful to Michael Landesmann and Robert Stehrer (wiiw), Neil Foster and Jesús Crespo Cuaresma (Department of Economics, University of Vienna) as well as Michael Peneder (Austrian Institute of Economic Research) for valuable comments. This research is based on Jubiläumsfondsprojekt Nr. 8954. Financial support by Oesterreichische Nationalbank is gratefully acknowledged.
}

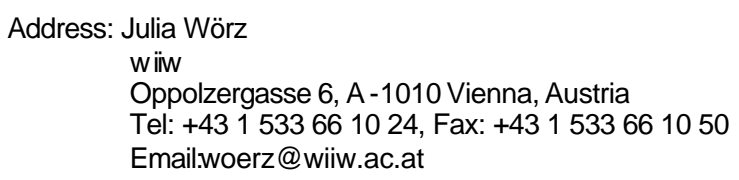




\section{Introduction}

It is a widely known and often confirmed fact that trade correlates positively and significantly with GDP growth. The literature is extensive in this respect and focuses more or less on various macroeconomic aspects of trade and growth, such as the impact of tariffs and trade policy as well as welfare implications of trade. Especially the link between aggregate exports and GDP growth has often been subjected to empirical tests. Most authors use export growth as the explanatory variable, sometimes an export ratio or the growth rate times the export ratio is used. Levine and Renelt (1992) and Greenaway et al. (1999) provide good overviews over the most commonly used explanatory variables in empirical growth regressions. According to these surveys, trade has a positive influence on growth. More precisely, most empirical studies (Edwards, 1998, Feder, 1983, Greenaway et al.,1999, Lee et al., 1998, Levine and Renelt, 1992, and Young, 1991, to cite just a few) find a positive effect of export growth on GDP growth. Levine and Renelt (1992) observe that the results of the growth equation remain essentially unchanged if measures of imports or total trade are used as explanatory variable instead of exports. Thus they conclude that, when testing the effect of exports on growth, one might interpret the results as measuring the effect of trade on growth more generally.

Both arguments, namely the positive impact of trade on growth and the equivalence of exports and imports or total trade in this respect, are challenged in a dynamic, multisectoral framework. This paper adopts a long-term view on the issue and analyses trade in different industries with respect to aggregate income growth. The long-run implications of trade in resource-based, low skill labour intensive industries can be expected to differ from those of trade in highly sophisticated technology and knowledge intensive industries. Further, exports and imports influence growth via different channels, whose relevance may also differ across industries.

Development economists often stress the developmental impact of exports. The argument is mostly based on the fact that the export sector has a higher productivity and a higher potential for economies of scale and positive externalities for the non-export sector in the form of knowledge spillovers, process and product innovation, technological change, etc. (Feder, 1983). Again, the argument has to be refined when transferred to a lower level of aggregation. Productivity, externalities and economies of scale are expected to differ between industries inside the export sector. Knowledge spillovers are presumably higher in high-tech industries than in low-tech, labour-intensive ones. This implies a significant influence of trade structure and trade specialization on development and also on economic growth. Further, the distinction between exports and imports becomes more pronounced at lower levels of aggregation. The scope for technology and knowledge spillovers is likely to be of much greater importance on the import side and is expected to increase in the technological sophistication of imports. On the other hand, productivity differentials and economies of scale are expected to play a greater role on the export side. 
In this paper the relationship between trade structure, trade specialization and aggregate income growth is empirically tested for a sample of 43 countries at different stages of development. Section 2 briefly reviews the literature on the link between trade and growth and adds some comments with respect to what is expected to change in a multi-sectoral framework. Section 3 describes industrial trade specialization patterns and decomposes each country's relative export performance into structural effects and growth in market share, using constant market share analysis. Section 4 links trade structure and trade specialization to GDP growth by incorporating structural variables in a fairly standard empirical growth model. Section 5 concludes.

\section{The link between trade and growth}

The idea that exports or trade relate positively with growth is not new and a number of arguments can be brought forward in favour of this link. Already in a static setting, a positive correlation between exports in general and GDP seems obvious. Other things equal, a rise in exports - by being a component of GDP - will always augment national income. By the same argument, specialization in exports of rapidly expanding sectors simply adds more to national income than specialization in other sectors. Apart from this growth accounting argument, a range of additional (dynamic) explanations can be found in the literature.

A common argument refers to the improved allocation of resources that is induced by opening up to trade on the export side. This leads to improvements in productivity for two reasons: First, a country will exploit comparative advantages and therefore specialize in the production of those goods which it can provide most efficiently. Second, producing for the world market often implies an upgrading in the quality of the products which leads to a rise in skill levels in the export sector. A higher exposure to the world market should induce the use of more modern techniques and create more competitive pressure feeding back positively on productivity. Using the same amount of inputs, higher productivity increases output. According to Verdoorn's law (based on Verdoorn, 1949), output growth will imply learning effects in the specific industry and consequently further add to productivity growth. Thus, exposure to the world market brings about positive dynamic growth effects.

Related to the above argument is the presumption that specialization according to comparative advantage also leads to the exploitation of economies of scale that could otherwise - i.e. by producing only for the limited demand from the dom estic economy - not have been realized. Thus, there is an indirect effect via increased external demand. Further, exports are often seen as a means to provide the economy with foreign exchange that can be used to purchase intermediate goods and to import capital and other assets from abroad (Chenery and Strout, 1966). Again, this leads to productivity gains accruing from exports or trade more generally. Rodrik (1989a, 1989b) stresses the indirect growth 
promoting effects that arise from imports of capital and technology and from embodied knowledge and technology in imported goods and defines exports merely as a means to enable a country to pay for its imports. This results from a very strict interpretation of new growth theories (Foster, 2001).

Most authors attribute exports as such also a prominent role as a source of learning and technology spillovers from abroad (Grossman and Helpman, 1991). Apart from the productivity differential between the export and the non-export sector, the export sector may provide the domestic economy with positive externalities in the form of knowledge and technology spillovers (Feder, 1983). In addition, by being exposed to more competitive world markets, the export sector is bound to develop more efficient production and management procedures which spill over into the domestic sector.

These latter arguments obtain special importance in a disaggregated framework, as is used in this paper. It seems plausible that indirect, dynamic effects vary across industries. First, productivity is higher in more sophisticated industries, which are in general more capital intensive and hence also more human capital intensive. Thus, knowledge and its dynamic growth effects play a greater role in these industries. Second, the scope for positive externalities (through learning and transfer of knowledge and technology) is increasing in the technology and skill content of the traded goods. Spillovers and other positive external effects are presumably higher in high tech, skill intensive sectors than in others. Further the impact of technological progress is greater in these sectors than in those employing already routinized production processes. Accordingly, trade in these industries should have a stronger and longer term impact on GDP growth than trade in less skill demanding industries. Equivalently, trade in industries with a large scope for economies of scale (i.e. less skill intensive industries like transport equipment, textiles, etc.) will have a positive impact on growth in the short and medium term. The latter argument refers to a temporary source of growth. These economies of scale have a static impact, they shift the country to a higher growth path, but do not provide additional growth once they are realized.

It follows from the above discussion that not trade as such matters, but the kind of trade (whether it occurs in low or high skill intensive industries) is important. Further, there are no simple and universally valid relationships to be expected between the industry structure of the export sector and growth. In addition to the beneficial effects provided by certain types of exports the exporting country must be at an appropriate stage of development in order to realize these gains. Depending on the absorptive capacity of a country - in terms of education of the labour force and the like - different industries will offer the greatest benefits from trade. It is still safe to say that in the course of development, the positive impact of trade will rise with the skill intensity of the respective industry. Consequently, trade in technology and skill intensive industries should play an important role for the most 
advanced countries, whereas less developed countries should reap greater benefits (i.e. receive more useful spillovers) from trade in medium skill intensive industries. Further, differences between exports and imports can be expected, as imports provide inputs into local production and are better suited to carry embodied knowledge and technology. On the other hand, high import penetration reduces the scope for learning by doing. Exports offer the possibility for learning effects, economies of scale and the like. Thus, the most beneficial industrial structure with respect to exports and imports may be different for different countries. Therefore, the equivalence of exports, imports and trade with respect to their impact on economic growth, which has been observed by Levine and Renelt (1992), may break down at the industrial level.

The effect of trade structure and trade specialization on aggregate growth has not been researched extensively in the literature. Recently, interest seems to emerge in linking structural developments to the aggregate level of income growth. ${ }^{2}$ A few empirical studies to mention are Amable (2000), Greenaway et al. (1999), Laursen (2000), and Peneder (2002), who all find positive effects from trade specialization on aggregate growth. Amable (2000) reports that already specialization as such turns out to be positive for a country, but especially specialization in the electronic industry. Most authors concentrate on the effects of specialization in specific activities and report a significant positive influence of some industries. Greenaway et al. (1999) identify the fuel, metals, and textiles industries as having a positive impact on developing countries' performance. Laursen (2000), using a sample of 18 OECD countries, finds evidence that specialization in the fastest growing sectors, in terms of export shares, correlates positively with GDP growth at the country level. He further observes that these sectors are in general identical to high-tech sectors. Peneder (2003) uses a sample of 28 OECD countries from 1990 to 1998 and finds that specialization in services represents a burden to future growth, because productivity gains are hard to achieve in this sector. For exports of technology driven and high skill intensive industries he finds positive effects on aggregate growth. He further observes a positive impact from increasing imports in the same industries.

\section{Structural change in trade patterns}

Industrial patterns of trade specialization for the same set of countries have been examined in more detail in a related paper (Wörz, 2003). ${ }^{3}$ Trade specialization is measured by a specific concept of revealed comparative advantage, namely the 'relative trade advantage' or 'revealed competitive advantage' developed in Vollrath (1991). This index calculates the relative representation of a country's exports and imports in one industry

\footnotetext{
2 The effects of export composition on productivity levels of respective sectors and industries is more straightforward to establish and has been researched somewhat more often, see for example Choudri and Hakura (2000), Fagerberg (2000), Keller (2000), Sharma (1996), Stehrer and Wörz (2002) and Timmer (2000).

3 Trade patterns are defined in terms of industrial patterns and not geographically (i.e. with respect to trading partners).
} 
compared to the average representation of that industry in total trade volume of the sample as a whole. The revealed competitive advantage is defined as follows:

$R C A_{i}^{c}=R X A_{i}^{c}-R M A_{i}^{c}$

where

$R X A_{i}^{c}=\frac{X_{i}^{c} / X_{n}^{c}}{X_{i}^{r} / X_{n}^{r}}$

and $R M A_{i}^{c}$ is defined analogously. $X_{i}^{c}$ are total exports (respectively imports) of country $c$ in industry $i$. Superscript $r$ denotes all countries without country $c$, and subscript $n$ refers to all industries except industry $i$. Industries have been aggregated into one of the four categories - low skill intensive, medium skill-blue collar workers, medium skill-white collar workers, and high skill intensive - yielding four distinct segments (see Appendix Table A).

A comparison of revealed competitive advantages between 1981 and 1997 for all five regions reveals the following patterns of specialization. There is a clear distinction of specialization between OECD North and all other regions in the sample, which has been more pronounced in the initial year. Whereas the advanced OECD countries are specialized in high skill industries, all other regions show a competitive advantage in the low skill segment. This picture has changed quantitatively, but not qualitatively, leading to more similar and less specialized trade patterns over time. The unambiguous trend towards de-specialization and convergence, even for this heterogeneous sample of countries, is remarkable. South Asia is the only region which has diverged in terms of trade structure from the average pattern of trade specialization. In general, specialization is stronger in high and low skill industries and weaker in medium skill industries. Further, specialization is stronger in exports, whereas imports have been more similar throughout the observation period.

It has already been mentioned above that exports or more precisely export growth correlates positively with income growth. Export growth can be attributed to the effect of growth assuming a constant structure and to the effect of structural change. Given that structural change, especially in exports, has been observed over the past two decades, this paper tries to isolate the impact of industrial structure and structural change on GDP growth. Before studying the effect of specific industries on growth, I shall look at the effect of structural change as such, which is isolated with the help of constant market share analysis. Therefore, changes in individual countries' export shares as a percentage of total exports in the sample are decomposed into a pure growth effect and the effects of structural change. This structural decomposition yields variables for structural change that 
will later be used in the growth regression. The decomposition is taken from Laursen (1998).

$$
\begin{array}{cc}
\Delta x_{c}=\sum_{i}\left(\Delta x_{i c} y_{i j}^{t-1}\right)+\sum_{i}\left(x_{i c}^{t-1} \Delta y_{i c}\right)+\sum_{i}\left(\Delta x_{i c} \frac{\Delta y_{i c}+\left|\Delta y_{i c}\right|}{2}\right)+\sum_{i}\left(\Delta x_{i c} \frac{\Delta y_{i c}-\left|\Delta y_{i c}\right|}{2}\right) \\
\text { MSE SME }
\end{array}
$$

where:

$$
\begin{aligned}
x_{c} & =\sum_{i} X_{i}^{c} / \sum_{i} \sum_{c} X_{i}^{c} & \ldots \text { a country's aggregate share of total exports in the sample; } \\
x_{i c} & =X_{i}^{c} / \sum_{c} X_{i}^{c} & \ldots \text { a country's share of a given industry in terms of exports; } \\
y_{i c} & =\sum_{c} X_{i}^{c} / \sum_{i} \sum_{c} X_{i}^{c} & \ldots \text { an industry's share of total exports in the sample; }
\end{aligned}
$$

and $X_{i}^{c}$ are exports from country $c$ in industry $i$.

The market share effect (MSE) indicates whether an expansion (or a contraction) of a country's exports relative to total exports in the sample is due to a gain (loss) in market shares, keeping the structure fixed. This may be seen as the "pure" growth effect. The structural market effect (SME) shows the effect of the initial specialization pattern on export growth, i.e. whether a country has showed a strong initial specialization in fast (or slow) growing industries. The market growth adaptation effect (MGAE) captures whether a country has changed its export structure in favour of sectors with fast (slow) growing exports worldwide. Finally, the market stagnation adaptation effect (MSAE) specifies a movement out of sectors with generally stagnating (fast) growing exports. The results of this decomposition are given in table 1.

Most OECD countries have lost export market shares and often so for the benefit of East Asian countries. Japan, Germany, France and the USA have experienced considerable declines in their overall market shares, whereas Singapore, Korea, Mexico and Thailand have been the greatest winners in the sample. These changes in market shares can be attributed mainly to pure growth effects. The contribution of initial specialization or changes therein is comparably small and often negligible. Industrial structure shows a greater effect in the case of advanced OECD countries than in any other group of countries. Further, these countries are often characterized by a beneficial initial pattern of specialization. Especially for the USA, a "good" specialization pattern in 1981 has reduced the loss in market shares considerably. In contrast, the initial structure of all East Asian countries has not added positively to their outstanding export performance. For them, restructuring

\footnotetext{
4 Note that Japan is included in OECD North and not in East Asia.
} 
towards fast growing industries has contributed to increases in export shares. At the same time, these countries also moved into slow rowing industries, thus lowering the potential total increase in their world export shares. The market stagnation adaptation effect is often negative. In contrast, the advanced OECD countries successfully moved out of stagnating industries, while at the same time they showed negative effects from not moving into fast growing sectors. Often, however, they have already been specialized in such industries (indicated by a positive structural market effect) and remained specialized there. This was the case for instance in the USA and Japan, but also in France, Germany and the UK.

In summary, whereas the positive effect of initial specialization (SME) plays the greatest role out of all three structural effects in the advanced OECD countries, structural change towards high growth sectors (MGAE) has been more important in East Asia. The rise in market shares of these countries, assuming a constant structure, has been further reinforced by a movement into the "right" sectors. To a lesser extent, Southern OECD countries also shifted export shares towards fast growing industries, while their initial structure did not prove beneficial. However, their increased representation on the world market is largely attributable to export growth and not to structural change. Likewise, for all remaining country groups, the effect of export structure and structural change on export growth has been extremely weak. One exception is Mexico, which showed some re structuring towards fast growing sectors, however it did not move out of slow growing industries at the same time. Thus, the two effects nearly cancelled each other out.

\section{Trade patterns and aggregate growth}

Given that indirect, dynamic effects from trade on growth vary across industries, it follows that trade in those industries, offering the greatest learning potential and technology and knowledge spillovers, should have the strongest impact on growth. Increasing export specialization in industries with a low scope for learning and/or spillovers may represent an impediment to long run growth. Thus, with respect to exports, we expect to see a positive effect from industrial upgrading. In contrast, high import penetration in labour intensive, low skill industries may free resources to be used more efficiently in other industries, thus increasing the long run growth rate. However, the effect of imports in more skill intensive industries is ambiguous. By incorporating intangible assets - such as knowledge and technology - they augment long run growth. On the other hand, by reducing the scope for learning by doing, they show a negative effect in the long run. In the present section empirical evidence is presented to support the hypotheses that, first, export specialization and import structure matter for growth, and second, the equivalence of exports and imports with respect to their impact on aggregate growth breaks down at the industrial level. ${ }^{5}$

\footnotetext{
The results are possibly weakened by relating growth in the economy as a whole to structural change in the manufacturing sector only. As no data for trade in primary commodities and in services are available from the same data sources, this shortcoming has to be accepted.
} 
Aggregate data for GDP, prices, investment and population are taken from the IMF's International Financial Statistics database. Real GDP per capita levels are expressed in 1995 purchasing power parities, obtained from the World Bank. Data on schooling is used from the Barro and Lee dataset. Disaggregated data on manufacturing exports and imports are taken from UNIDO Demand and Supply Balance Database.

The sample is split into two groups of countries: OECD refers to a set of OECD member countries up to $1994 .{ }^{6}$ Further, a group of catching-up countries is included, consisting of selected Asian and Latin American countries. Industries are defined at the three digit level, using the ISIC, rev.2 classification. ${ }^{8}$ The observation period extends from 1981 to 1997.

The empirical framework uses elements from 'classic' and 'new' growth models, adopting a supply side point of view. The dependent variable is real GDP per capita growth. Population growth and the investment ratio (as a proxy for growth of the capital stock) are included as the two most important explanatory variables. Investment is one of the rare variables that can always robustly be associated with GDP growth (Leamer, 1983; Levine and Renelt, 1992; Sala-i-Martin, 1997). The level of initial GDP per capita is included to control for the initial stage of development (i.e. reveal convergence). Further, a variable of schooling in the initial year is introduced to account for differences in human capital. Especially the inclusion of the rapidly industrializing East Asian economies on the one hand and the slowly progressing South Asian countries on the other hand seems to call for including such conditioning variables. Thus, the benchmark specification is given below:

$$
\begin{aligned}
\Delta \ln G D P_{t}^{c}= & \alpha+\varphi \Delta \ln G D P_{t-j}{ }^{c}+\beta_{1} \Delta I N V_{t}{ }^{c}+\beta_{2} \Delta \ln P O P_{t}^{c}+ \\
& +\beta_{3} \ln G D P 0^{c}+\beta_{4} S C H^{c}+\varepsilon_{t}{ }^{c}
\end{aligned}
$$

where

$G D P_{t}^{c}=\quad$ real GDP per capita,

$I N V_{t}^{c}=\quad$ investment ratio,

$P O P_{t}^{c}=\quad$ population,

$G D P 0^{c}=$ GDP per capita (in ppps) in 1981,

6 These are Australia, Austria, Canada, Denmark, Finland, France, Germany, Greece, Iceland, Italy, Japan, The Netherlands, New Zealand, Norway, Portugal, Spain, Sweden, Turkey, the UK and the USA.

7 East Asia: Hong Kong, Indonesia, South Korea, Malaysia, the Philippines, Singapore and Thailand; South Asia: Bangladesh, Sri Lanka, India, Nepal and Pakistan; Latin America: Argentina, Bolivia, Chile, Columbia, Ecuador, El Salvador, Guatemala, Mexico, Nicaragua, Panama, Peru, Uruguay, and Venezuela.

8 Two industries - drugs and medicine and the manufacture of aircraft - were extracted at the four digit level, in order to take account of their high skill intensity. 
$S C H^{c}=\quad$ fraction of the population aged 15+ which has completed secondary schooling as highest education in 1981,

This benchmark model is in the following augmented by various variables that measure structural change in export patterns, trade structure and trade specialization. A dynamic panel was estimated using the one-step GMM estimator developed by Arellano and Bond (1991). ${ }^{9}$ The parameters were estimated for the total sample and separately for the subsample of OECD countries and the subsample of all remaining countries.

In the first specification (see equation 4.2), the components from the constant market share analysis in section 3 are used to highlight the impact of structural change in exports as such on aggregate growth.

$$
\begin{aligned}
\Delta \ln G D P_{t}^{c} & =\alpha+\varphi \Delta \ln G D P_{t-j}{ }^{c}+\beta_{1} \Delta I N V_{t}^{c}+\beta_{2} \Delta \ln P O P_{t}^{c}+ \\
& +\beta_{3} \ln G D P 0^{c}+\beta_{4} S C H^{c}+ \\
& +\beta_{5} M S E_{t-1}{ }^{c}+\beta_{6} S M E_{t-1}{ }^{c}+\beta_{7} M G A E_{t-1}{ }^{c}+\beta_{8} M S A E_{t-1}{ }^{c}+\varepsilon_{t}{ }^{c}
\end{aligned}
$$

The results are presented in table $2 .{ }^{10}$ Apart from the investment variable, all coefficients of the standard growth model show the expected sign. There is a high degree of positive but diminishing autocorrelation in the dependent variable. The first two lags of GDP per capita growth are both highly significant. Population growth relates negatively to per capita GDP growth, which is to be expected. Initial GDP is again negatively related, implying convergence in the sample as a whole. However, the coefficient is not significant for the subsample of developing countries. In this rather heterogeneous sample, including industrialized countries on the one hand and developing and less developed Asian countries on the other hand, convergence occurs mainly inside the group of richer countries. ${ }^{11}$ Human capital as measured by secondary schooling is never found to be significant. Further, none of the variables that capture structural change is significant. This first result suggests that structural change on the export side did not have any impact on long run development.

9 The dynamic specification w as chosen, because this allows to identify long term developments on the one hand and on the other hand avoids the problem of endogeneity in statistical terms, which is naturally present when looking at trade patterns and growth. Further the structural variables will be entered with one time lag to capture the structural impact on growth without endogeneity.

10 As the change in market share, to which the four components add up to, is not constant over time, there is no problem of multicollinearity in the data when all four effects are included.

11 This is a general empirical regularity about growth when referring to absolute convergence; see Barro (1991), Barro and Sala-i-Martin (1992), and Mankiw, Romer, and Weil (1992). Often conditional convergence is found in broader samples. In the present sample, where growth is conditioned the initial level of secondary schooling, conditional convergence was again present in the sample as a whole and in the subsample of OECD countries but not inside the group of less developed countries. 
When the sample is split into highly industrialized and catching-up countries, an interesting distinction between the two groups of countries is revealed. As a general remark, the model seems to explain income growth in OECD countries fairly well, whereas it performs considerably worse for the group of catching-up countries. For the subsample of OECD members, the investment variable is highly significant and positive. The fact that investment has no significant impact on economic growth in developing countries may reflect high investment ratios on average. Due to weak or often lacking health and social security systems, substantial (predominantly public) funds are invested in these sectors. This results in high investment ratios also for slow growing countries (like India for instance).

More importantly, in the high income sample the structural market effect (SME) is significantly positive implying a beneficial effect of the initial pattern of trade specialization on subsequent GDP per capita. Further, the significantly positive coefficient on the market share adaptation effect (MSAE) indicates that OECD countries successfully reduced their exports in slow growing sectors. None of the variables capturing structural change in the catching-up countries shows any effect on growth. The movement into fast growing export industries, which was observed for the East Asian countries, did not result in a positive effect on per capita income growth for the group as a whole.

Structural change as such did not turn out to play an important role in this framework. Although structural change in manufacturing exports was related to growth in OECD countries, there was no significant relationship in the subsample of catching-up countries. The guiding hypothesis in this paper is, however, more specific. In the next step, I shall therefore analyse the impact of specific export (and import) patterns on growth. The baseline model is now augmented by the industrial composition of exports and imports in each country. Trade structure is measured by changes in individual export (import) shares in relation to GDP, again entered with a lag of one period. Industries are grouped into four broadly defined categories which differ in their skill intensity (Peneder, 1999). A list of all industries and their classification is given in the appendix. This allows to test for a potential beneficial effect of skill-upgrading in trade patterns on development. The empirical specification is now given as follows:

$$
\begin{aligned}
\Delta \ln G D P_{t}^{c}= & \alpha+\varphi \Delta \ln G D P_{t-j}{ }^{c}+\beta_{1} \Delta I N V_{t}^{c}+\beta_{2} \Delta \ln P O P_{t}{ }^{c}+ \\
& +\beta_{3} \ln G D P 0^{c}+\beta_{4} S C H^{c}+\sum_{i} \gamma_{i} \Delta T R S H_{i, t-1}^{c}+\varepsilon_{t}{ }^{c}
\end{aligned}
$$

TRSH refers to the share of exports (imports respectively) over GDP in the respective industry segment $i$ (low to high skill) of country $c$ at time $t-1$. 
As outlined above, the growth effect of trade shares in individual industries is expected to differ in various respects. According to the previous arguments, there should be a negative impact of a growing share of low skill intensive exports as opposed to a positive influence from a growing share of high skill exports. Although in the short run, economies of scale in lower skill intensive industries - which arise from serving a larger market - may play a role for the subsample of less developed countries, we do not expect to see a positive coefficient given the length of the observation period.

In contrast to the effect of aggregate trade flows on GDP, which might be rather similar regardless whether exports or imports are used as explanatory variables, the relationship between trade structure and growth may well be different for exports and imports at the industrial level. Industrial export patterns are more likely to be determined by factor endowments than import patterns. The latter are strongly demand driven, and should be rather similar for countries with similar levels of GDP per capita. As a result, the correlation between import structure and GDP growth is expected to be stronger. Assuming that imports matter for growth via inflows of intangible assets, a positive correlation between rising import shares in all skill categories and income growth can be expected. If further the value of such assets increases in the skill intensity of the imported goods, structural change towards more skill intensive imports should have a greater positive impact on GDP. Conversely, the reduced scope for learning by doing that will also follow from a high import penetration may represent an impediment to long run growth. Thus, the net effect is ambiguous a priori and depends very much on the specific circumstances. If imports serve as intermediate inputs they are likely to embody intangible assets and they may induce learning effects. If, on the other hand, imports merely substitute consumption goods, these positive effects are less likely to occur. High imports in skill intensive industries may then even reduce learning effects in such a case.

Table 3 reports the results that are obtained from regressing GDP growth on changes in the export structure as set out in equation 4.3. ${ }^{12}$ The effect of rising lower skill exports turns out to be insignificant for growth. Export shares in medium high skill intensive categories were significantly positively correlated with per capita income growth. High tech exports even showed a weakly significant negative correlation to GDP growth. Again, the results are modified when stratifying the sample according to income levels. For the high income countries, low skill exports do not matter. In line with our expectation, growing shares of medium skill intensive exports relate positive with GDP growth. In contrast to this, increasing exports in the three high skill intensive industries show a negative sign. This is somewhat surprising and might be explained by a resource constraint: It could be that these industries do not achieve productivity levels comparable with those of more

12 Again, no indication of multicollinearity in the data was present, when using all four trade shares (which sum up to different values for each year, as the degree of openness varies over time). Therefore they were all jointly included. 
routinized, less skill intensive ac tivities. Thus, they would bind resources (especially human capital) that could be more efficiently employed in other industries. ${ }^{13}$

For the subsample of developing countries, growing low skill exports exert a positive influence on growth. These are the industries where developing countries usually hold their comparative advantages. In line with the Ricardian prediction, exploiting these existing comparative advantages turned out to improve the growth performance on these countries over the observation period. Further, a positive influence of medium high skill intensive exports could be observed and again the negative relationship between high skill industries and growth.

Table 4 presents the results that are obtained when using imports instead of exports. The general positive influence from rising medium high skill intensive imports stems from the subsample of developing countries only. This might be related to important knowledge and technology spillovers which occur due to trade in the goods that are produced in these industries. No such effect was seen in the group of highly developed countries. For this group, there is an inverse relationship between skill intensity of imports and economic growth. While low skill imports add positively to growth, medium low skill intensive imports show a negative impact, which carries through to the total sample. There are no effects from higher skill imports as in developing countries, where only medium high skill imports matter. In analogy to what has been said above, this inverse relationship can be explained by the following: imports in lower skill industries free resources to be used more efficiently in the more capital intensive high skill industries offering also higher productivity levels. Again, the model performs worse when applied to the group of developing countries, with some of the variables that influence growth in the OECD countries (investment and initial GDP) remaining insignificant or being only weakly significant.

It is also likely that trade specialization rather than trade structure is important - i.e. a country's trade structure with respect to the average trade structure in the world market. This corresponds to competitiveness and could thus be more appropriate than country specific export and import shares. It seems plausible that countries which are competitive on the world market experience a better growth performance. Again, this precludes any a priori statements about which industries are going to be growth enhancing. In the Ricardian spirit, hose countries that specialize according to their comparative advantages should grow faster than others. In a dynamic framework, where comparative advantages are allowed to develop endogenously (see Redding, 1999, for a formal discussion of this idea) specialization according to existing comparative advantages is not necessarily growth

13 The results may be weakened here by aggregating industries into four broad categories, using a classification that has been developed on the basis of OECD employment data for a relatively small set of countries in the early nineties. It is thereby assumed that the skill intensity of industries remains constant over time and constant across countries. Especially the latter assumption may be violated when comparing highly industrialised countries to less developed countries. 
enhancing in the long run. In this framework, specialization in those industries which offer the greatest learning effects is optimal. Thus, again specialization in more skill intensive industries should result in a higher long term growth rate.

Trade specialization is measured by the revealed competitive advantage given in equation 3.1. Table 5 reports the results of the following estimation:

$$
\begin{aligned}
\Delta \ln G D P_{t}^{c} & =\alpha+\varphi \Delta \ln G D P_{t-j}{ }^{c}+\beta_{1} \Delta I N V_{t}^{c}+\beta_{2} \Delta \ln P O P_{t}^{c}+ \\
& +\beta_{3} \ln G D P 0^{c}+\beta_{4} S C H^{c}+\sum_{i} \gamma_{i} R C A_{i, t-1}^{c}+\varepsilon_{c}
\end{aligned}
$$

where $R C A_{i}^{c}$ refers to the revealed competitive advantage in individual 3-digit industries (and two 4-digit industries: pharmaceutical products and manufacture of aircrafts). ${ }^{14}$ As in all previous specifications, population growth showed the expected sign while investment was significant only in the subsample of OECD countries. Convergence is observed for the sample as a whole and the subset of developing countries only and secondary schooling (to proxy for human capital) is only significant in the aggregate sample.

Trade specialization matters in about one third of all included industries. For the sample as a whole, specialization in more skill intensive industries turns out to have a significant impact on growth relatively more often than specialization in less skill intensive activities. This takes account of the fact that 19 out of thirty industries are classified as low and medium low skill intensive. Further, those low skill industries that are significant in the growth equation often show a negative coefficient. For example, specialization in tobacco (ISIC code 314), wearing apparel (322), and minerals (369) relates to subsequent lower growth. On the other hand, there are also low skill activities with a positive impact, like the manufacture of non-ferrous metals (372), and food products (311). The latter result can be traced to the subsample of catching-up countries. These countries also profit from strong trade specialization in another low skill, blue collar industry, namely other manufactured products (390). This rather diverse industry comprises for instance sporting goods, toys, jewellery and clearly plays an important role in developing economies.

The category of medium skill, white collar activities is particularly interesting. Nearly half of the industries in this category have a significant impact on GDP growth. The positive growth effect of specialization in other chemicals (352, excluding pharmaceuticals) and electrical machinery (383, including radio, TV and communication equipment) lends again support to the hypothesis that specialization in more sophisticated industries is beneficial for growth in the long run. The significantly negative coefficient on printing and publishing (342) is surprising and does not fit into this picture. This is also the only industry with a

14 The RCA indices were transformed by (RCA2-1)/(RCA2+1), as proposed by Grupp (1994). This helped to remedy the problem of non-normally distributed residuals. 
significant and the same effect on growth in all variations of the sample. Finally, when looking at the high skill segment, one industry shows a significant coefficient. A negative impact from specialization in pharmaceuticals (3522) is observed in the aggregate sample. Again, the result arises from the subsample of less developed countries and will be discussed below.

Stratifying the sample into OECD and non-OECD countries reveals an interesting distinction between the two groups. With respect to the latter group, specialization in low and medium low skill activities often shows a beneficial influence on long term economic development. The converse holds true for OECD members. Here, trade specialization in a few low skill industries, i.e. tobacco (314), minerals (369), transport machinery (384, excluding aircraft), has a significantly negative impact on future growth. Specialization in only two low skill industries, wearing apparel (322) and pottery (361), exhibits a weakly significant positive influence on growth. In line with our hypothesis, trade specialization in more skill intensive industries is often rewarded by a stronger growth performance. Specialization in industrial chemicals (351) and non-electrical machinery (382) ${ }^{15}$ exhibits a significant and positive coefficient in the growth equation. Further, specializing in exporting petrol and coal (ISIC code 354) is also conducive for high growth. However, this industry is certainly a special case, given the product it manufactures, and should not be stressed here as evidence for the positive relationship between skill intensity and growth.

The subsample of catching-up countries reveals a different relationship between trade specialization and growth. The observation that the coefficients on individual industries are more often significant suggests that specialization patterns matter even more importantly than in OECD countries. However, in sharp contrast to high income countries, specialization in low skill industries is always beneficial for growth while specialization in high skill industries often shows a negative influence. More specifically, trade specialization in the food, beverages, and plastic industries (ISIC codes 311, 313, and 356) induces higher growth in this subsample. As mentioned before, also the manufacture of diverse items such as jewellery, music instruments, sporting goods, etc. (other manufactured products, code 390) has a strong positive influence on these economies. Similar to the subsample of OECD members, specialization in medium high skill intensive industries relates very often to a better growth performance. It is interesting to note that the nonOECD countries take advantage from specializing in distinct industries compared to OECD countries. High relative net exports in the following industries correspond with higher GDP growth: paper, other chemicals (excluding drugs and medicine), petroleum refineries, and electrical machinery (codes $341,352,353,383$ ). However, in contrast to their OECD

15 As mentioned previously, the data provided by UNIDO is classified according to revision 2 of the ISIC nomenclature. In contrast to the latest revision, computers are still subsumed in the non-electrical machinery industry (code 382) which is clearly not appropriate today. This also explains why this industry is classified as being more skill intensive than electrical machinery (code 383). 
trading partners, specialization in high skill intensive industries seems to hamper growth rather than speed it up. This is reflected by the negative coefficients on electrical machinery and drugs and medicine.

The fact that specialization in the most skill intensive industries slows down growth in less developed countries while boosting growth in already highly developed countries can be explained by a better use of resources (or more appropriate resource endowments, i.e. abundance of highly skill labourers) in the latter countries. Again the resource binding constraint mentioned earlier can be quoted in this context. The strong and positive impact of medium high skill industries is also in line with previous observations and stresses the important role of these activities. Their ability to allow for positive externalities while being relatively easily adapted by less developed economies can serve as one explanation for their importance in the course of economic development.

\section{Conclusion}

The paper investigated the relationship between trade structure, trade specialization and per capita income growth for a heterogeneous set of countries. These issues have not often been researched, partly due to the fact that they combine two important strands of economic theory, which have explicitly been combined only recently. In general, growth theories remain on the aggregate, economy wide level. On the other hand, trade theories are primarily concerned with explaining the determinants of trade and trade structure or specialization and do not provide general predictions concerning the impact of trade structure and specialization on growth. Some empirical studies exist which focus explicitly on this link. They focus either on industrialized or on developing countries separately. The present sample includes highly and less developed countries as well as rapidly developing countries and thus allows us to take a more general look at the link between trade structure and growth. The results indicate that there is no universally valid model which would describe this link. Rather, the relationship between trade structure and growth is a different one for countries at different stages of development.

The research was guided by the hypothesis that different types of exports (or imports) have a differential effect on growth. The empirical evidence has been supportive for this hypothesis at large. More specifically, the research was initially guided by the idea that skill upgrading in trade patterns would result in a better growth performance. This hypothesis was only partly confirmed. Trade in medium skill, white collar industries emerged as having a clear positive influence on long run growth. This result was observed when testing for the impact of export structure, import structure as well as trade specialization. Thus, an important role can be ascribed to medium high skill activities, but not to the most skill intensive industries. This is intuitively appealing as these industries offer a large potential for positive external effects (in form of knowledge and technology spillovers) while still 
being relatively open to access by less developed economies. In contrast, the effect of a large share of high skill exports was found to be negative. Likewise specialization in those industries often corresponded to slower economic growth, especially so in less developed countries. This may be explained by a resource binding constraint and still relatively low productivity levels in these cutting-edge industries.

Another finding revealed that the effect of trade specialization and structural change in trade patterns differed greatly between the subsample of highly industrialized OECD member countries and developing Asian and Latin American countries. This shows the importance of an "appropriate" structure that corresponds best to the respective stage of development. While a high share of low skill intensive exports exhibited a positive influence on growth in catching-up economies, the same relationship was insignificant for OECD members. In contrast, a high share of low skill intensive imports translated to faster growth in these countries (probably because this frees scarce resources that are then available for use in other more sophisticated activities), while no significant relationship could be established here for less developed countries. These economies rather gained from importing in medium high skill intensive industries. The distinction between OECD and non-OECD countries became more pronounced when focussing on specialization patterns across individual industries. Here, a clear distinction between specialization patterns even inside skill categories could be seen. This suggests that inter industry trade not only plays a major role between countries at different stages of development (in line with mainstream trade theories), but also that this kind of trade specialization is economically beneficial for both partners.

Further, the difference between export and import patterns with respect to their impact on GDP growth hints towards different channels by which export and import structure relate to aggregate development. On the export side, improved resource allocation, technology and knowledge spillovers and other positive externalities are the main arguments for a positive relationship. Consequently, the positive impact of exports on income growth is increasing in the skill intensity of exports. On the import side, again spillovers via embodied knowledge and other assets are put forward in favour of a positive impact for growth. However, imports can also reduce learning by doing. Thus, the negative correlation which was observed between the skill intensity of imports and growth in the OECD subsample may reflect the greater importance of learning by doing in more skill intensive industries. Finally, two remarks should be made: First, the issue of causation remains unclear in the context of trade and growth. Although one is tempted to assign a causal role to trade when interpreting the results, I have not made any attempt to test for causation in the present paper. The issue of causation has been dealt with insofar, as all structural variables were entered with a lag of one period in the regressions. Second, the link between trade structure and growth could be different if all sectors had been included. Due to data constraints, the analysis refers only to the manufacturing sector. Thus, further research is 
necessary to extend the focus on trade in agriculture, utilities and producer services, especially when dealing with developing countries. 


\section{References}

Amable, B. (2000); International Specialisation and Growth; Structural Change and Economic Dynamics, 11(4), 413-432.

Arellano, M. and S. Bond (1991); Some Tests of Specification for Panel Data: Monte Carlo Evidence and an Application to Employment Equaions, Review of Economic Studies, 58, 277-297.

Barro, R.J. (1991); Economic Growth in a Cross Section of Countries; Quarterly Journal of Economics 106 (2), 407-443.

Barro, R.J. and X. Sala-i-Martin (1992); Convergence; Journal of Political Economy100 (2), 223-251.

Borkakoti, J. (1998); International Trade: Causes and Consequences; London: MacMillan.

Chenery, H.B. and A. Strout (1966); Foreign Assistance and Economic Development; American Economic Review66, 679-732.

Choudri, E. and D. Hakura (2000); International Trade and Productivity Growth: Exploring the Sectoral Effects for Developing Countries; IMF Staff Papers 47(1), 30-53.

Edwards, S. (1998); Openness, Productivity and Growth: What do we really know?; The Economic Journal 108, 383-398.

Fagerberg, J. (2000); Technological progress, structural change and productivity growth: a comparative study; Structural Change and Economic Dynamics 11(4), 393-412.

Feder, G. (1983); On Exports and Economic Growth; Journal of Development Economics 12, 59-73.

Foster, N. (2001); North -South Trade, Openness and Growth, PhD Thesis, University of Nottingham, UK.

Greenaway, D., W. Morgan and P. Wright (1999); Exports, export composition and growth; Journal of International Trade and Economic Development8(1), 41-51.

Grossman, G.M. and E. Helpman (1991); Trade, Innovation, and Growth in the Global Economy; MIT Press, Cambridge, Mass.

Grupp, H. (1994); The measurement of Technical Performance of Innovations by Technometrics and Its Impact on Established Technology Indicators; Research Policy 23 (2), 175-193.

Keller, W. (2000); Do Trade Patterns and Technology Flows Affect Productivity Growth?; The World Bank Economic Review14, No.1, 17-47.

Laursen, K. (2000); Trade Specialisation, Technology and Economic Growth: Theory and Evidence from Advanced Countries; Cheltenham, UK: Edward Elgar.

Laursen, K. (1998); How Structural Change Differs, and Why it Matters (for Economic Growth); DRUID Working Paper No. 98-25.

Leamer, E.E. (1983); Let's take the Con out of Econometrics, American Economic Review73, 31-43.

Lee, M., R. Longmire, L. Matyas and M. Harris (1998); Growth Convergence: some panel data evidence; Applied Economics 30, 907-912.

Levine, R. and D. Renelt (1992); A Sensitivity Analysis of Cross-Country Growth Regressions; American Economic Review82(4), 942-980.

Mankiw, G., D. Romer, and D. Weil (1992); A Contribution to the Empirics of Economic Growth; Quarterly Journal of Economics 107 (2), 407-437.

Peneder, M. (2003); Industrial Structure and Aggregate Growth; Structural Change and Economic Dynamics Structural Change and Economic Dynamics, Vol 14(4), 427-448. 
Peneder, M. (1999); Intangible investment and human resources the new 'WIFO taxonomy of manufacturing industries; WIFO Working Paper 114.

Redding, S. (1999); Dynamic comparative advantage and the welfare effects of trade; Oxford Economic Papers 51, 15-39.

Rodrik, D. (1989a); Promises, Promises: Credible Policy Reform via Signalling; Economic Journal99, 756-772.

Rodrik, Dani (1989b); Credibility of Trade Reform: A Policy-Maker's Guide; The World Economy 1, 1-16.

Sala-i-Martin, X. (1997); I just ran two million regressions; American Economic Review87, 178-183.

Sharma, K. (1996); Trade-Orientation and Productivity Growth: A Review of the Theoretical Framework in the Context of Land-Locked Economies; Indian-Economic-Journal 43(3), 89-99.

Stehrer, R. and J. Wörz (2002); Industrial Diversity, Trade Patterns and Productivity Convergence, WIIW Working Paper23.

Timmer, M. (2000); The Dynamics of Asian Manufacturing; A Comparative Perspective in the Late Twentieth Century; Cheltenham: Edward Elgar.

Verdoorn, P. J. (1949); Fattore che Regolano lo Sviluppo Della Produttivita del Lavoro; L'Industria 1, 3-10.

Vollrath, T. L. (1991); A theoretical evaluation of alternative trade intensity measures of revealed comparative advantage; Weltwirtschaftliches Archiv127, 265-280.

Wörz, J. (2003); Industrial Trade Specialisation and Economic Growth, Dissertation, University of Vienna.

Young, A. (1991); Learning by doing and the dynamic effects of international trade; Quarterly Journal of Economics 106(2), 369-405. 


\section{Appendix}

Table A: List of industries and grouping according to skill intensity

\section{ISIC Code Definition}

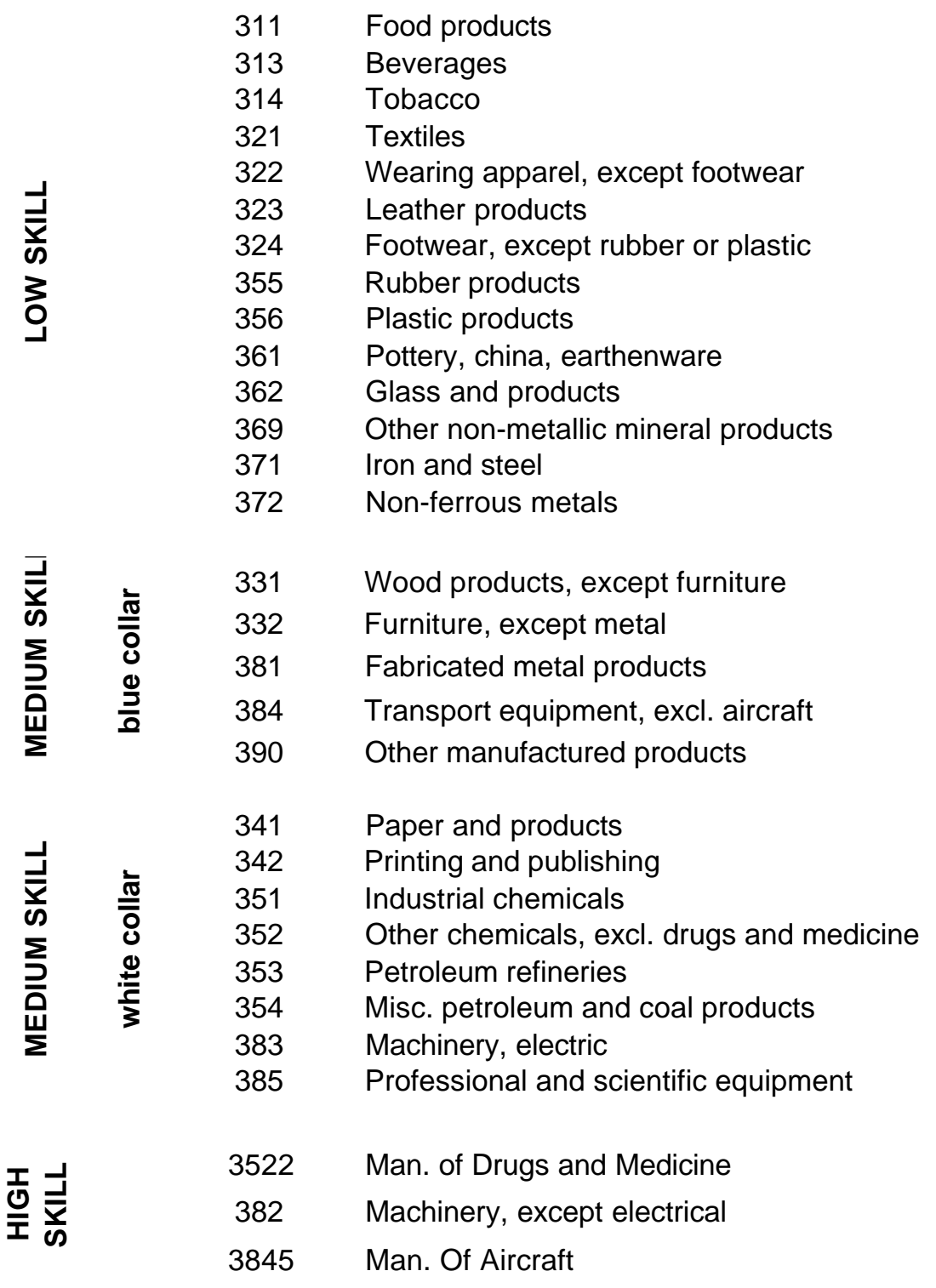


Tables

Table 1

\section{Decomposition of growth in market shares, 1981-1997}

$\underset{\text { market share }}{\text { growth in }}=\underset{\text { effect }}{\text { market share }}+\quad \begin{gathered}\text { structural } \\ \text { market effect }\end{gathered}$

OECD North

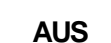

AUT

CAN

DNK

FIN

FRA

GER

ITA

JPN

NLD

NZL

NOR

SWE

GBR

USA

OECD South

GRC

PRT

ESP

TUR

East Asia

HKG

IDN

KOR

MYS

PHL

SGP

THA

South Asia

BGD

SRL

IND

NPL

PAK

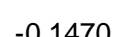

$$
-0.3768
$$$$
-0.6946
$$$$
-0.1914
$$$$
-0.1786
$$$$
-1.5632
$$$$
-2.9593
$$$$
-0.3514
$$$$
-3.5309
$$

0.7211

$$
-0.1533
$$$$
-0.3283
$$$$
-0.2583
$$$$
-0.5156
$$$$
-1.2505
$$

$$
-0.0608
$$$$
0.3788
$$$$
0.9838
$$

0.2841

$-0.4338$

0.6409

2.0862

0.9452

0.2731

3.0148

1.0004

0.063

$-0.0247$

0.1768

0.0051

0.0316

$$
\text { effect }
$$

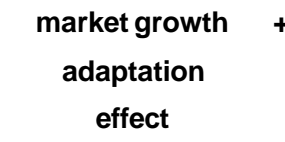

$\begin{array}{lll} & & \text { effect } \\ 0.0154 & + & 0.0326 \\ -0.0314 & + & 0.0378 \\ -0.1405 & + & 0.0314 \\ -0.0040 & + & 0.0166 \\ -0.0085 & + & 0.0211 \\ -0.0896 & + & 0.1168 \\ -0.3745 & + & 0.1151 \\ -0.0315 & + & -0.0505 \\ -0.1347 & + & 0.4010 \\ 0.0670 & + & 0.0041 \\ -0.0011 & + & 0.0203 \\ -0.0252 & + & 0.0235 \\ -0.0168 & + & 0.0122 \\ -0.0612 & + & 0.0345 \\ -0.1881 & + & -0.0331 \\ & & \\ -0.0011 & + & 0.0025 \\ 0.0110 & + & -0.0603 \\ 0.0350 & + & -0.0808 \\ 0.0116 & + & -0.0543\end{array}$

(Table 1 continued)

effect

0.0378

0.0166

0211

0.1168

0.0505

0.4010

0.0203

0.0345

$\begin{array}{lllll}0.0197 & + & -0.0582 & + & 0.0221 \\ -0.0108 & + & 0.0280 & + & -0.0907 \\ -0.0856 & + & 0.1969 & + & -0.1213 \\ -0.0238 & + & 0.1162 & + & -0.0391 \\ -0.0473 & + & 0.0597 & + & 0.0206 \\ -0.0059 & + & 0.3401 & + & -0.0782 \\ -0.0733 & + & 0.0889 & + & -0.0735 \\ & & & & \\ -0.0088 & + & 0.0004 & + & -0.0185 \\ -0.0045 & + & -0.0002 & + & 0.0047 \\ -0.0381 & + & 0.0116 & + & -0.0355 \\ -0.0007 & + & -0.0001 & + & -0.0017 \\ -0.0407 & + & -0.0003 & + & -0.0194\end{array}$

market

stagnation

adaptation

$\begin{array}{lll}-0.0432+0.0011+ & 0.0025\end{array}$

$\begin{array}{lll}-0.0104+0.0110+ & -0.0603\end{array}$

$\begin{array}{lll}-0.1041+0.0350+ & -0.0808\end{array}$

$\begin{array}{lll}-0.0286+0.0116+ & -0.0543\end{array}$ 
Table 1 (continued)

Decomposition of growth in market shares, 1981-1997

\begin{tabular}{|c|c|c|c|c|c|c|c|c|c|}
\hline Latin America & $\begin{array}{c}\text { growth in } \\
\text { market share }\end{array}$ & $=$ & $\begin{array}{c}\text { market share } \\
\text { effect }\end{array}$ & + & $\begin{array}{c}\text { structural } \\
\text { market effect }\end{array}$ & + & $\begin{array}{c}\text { market growth } \\
\text { adaptation } \\
\text { effect }\end{array}$ & + & $\begin{array}{c}\text { market } \\
\text { stagnation } \\
\text { adaptation } \\
\text { effect }\end{array}$ \\
\hline ARG & 0.0466 & $=$ & 0.1244 & + & -0.0646 & + & -0.0007 & + & -0.0125 \\
\hline BOL & -0.0195 & $=$ & -0.0161 & + & -0.0070 & + & -0.0001 & + & 0.0037 \\
\hline CHL & 0.0525 & $=$ & 0.1078 & + & -0.0408 & + & 0.0028 & + & -0.0171 \\
\hline COL & -0.0297 & $=$ & -0.0102 & + & -0.0271 & + & 0.0025 & + & 0.0052 \\
\hline ECU & -0.0176 & $=$ & -0.0123 & + & -0.0081 & + & -0.0001 & + & 0.0028 \\
\hline SLV & -0.0213 & $=$ & -0.0191 & + & -0.0051 & + & -0.0005 & + & 0.0035 \\
\hline GTM & -0.0375 & $=$ & -0.0300 & + & -0.0108 & + & -0.0014 & + & 0.0046 \\
\hline MEX & 2.4400 & $=$ & 2.4222 & + & -0.0243 & + & 0.1815 & + & -0.1394 \\
\hline PAN & -0.0130 & $=$ & -0.0118 & + & -0.0029 & + & 0.0001 & + & 0.0016 \\
\hline PER & 0.0043 & $=$ & 0.0354 & + & -0.0207 & + & -0.0011 & + & -0.0092 \\
\hline URY & -0.0337 & $=$ & -0.0192 & + & -0.0192 & + & 0.0001 & + & 0.0046 \\
\hline VEN & 0.0420 & $=$ & 0.0579 & + & -0.0106 & + & 0.0025 & + & -0.0078 \\
\hline
\end{tabular}


Table 2

Effect of structural change on income growth, 1981-1997

Dependent variable: $\Delta$ In real GDP p.c. at ppp - A-B (one step)

\begin{tabular}{|c|c|c|c|}
\hline & total sample & OECD & non-OECD ${ }^{1)}$ \\
\hline \multirow[t]{2}{*}{$\Delta \operatorname{lnGDP} P_{t-1}$} & $1.1283^{* \star *}$ & $0.7208^{* \star *}$ & 1.0678 *** \\
\hline & 0.000 & 0.000 & 0.000 \\
\hline \multirow[t]{2}{*}{$\Delta \operatorname{lnGDP} P_{t-2}$} & $-0.2692^{* * *}$ & $-0.2634^{* * *}$ & $-0.2504^{* * *}$ \\
\hline & 0.000 & 0.000 & 0.000 \\
\hline \multirow[t]{2}{*}{$\triangle \mathrm{InPOP}$} & $-0.2063^{* * *}$ & $-0.5055^{* * *}$ & -0.4620 *** \\
\hline & 0.001 & 0.000 & 0.007 \\
\hline \multirow[t]{2}{*}{$\Delta \mathbb{I N V}$} & 0.0003 & $0.5595^{* \star *}$ & 0.0026 \\
\hline & 0.986 & 0.000 & 0.790 \\
\hline \multirow[t]{2}{*}{ InGDP0 } & $-2.14 \mathrm{E}-03^{* * *}$ & $-3.10 \mathrm{E}-03^{* * *}$ & $-1.33 E-03$ \\
\hline & 0.001 & 0.010 & 0.209 \\
\hline \multirow[t]{2}{*}{ LSCO } & $1.13 \mathrm{E}-04$ & $-1.67 \mathrm{E}-05$ & $1.40 \mathrm{E}-04$ \\
\hline & 0.122 & 0.743 & 0.462 \\
\hline \multirow[t]{2}{*}{ MSE $_{-1}$} & 0.1850 & 0.3695 & 3.4710 \\
\hline & 0.836 & 0.361 & 0.500 \\
\hline \multirow[t]{2}{*}{$\mathrm{SME}_{\mathrm{t}-1}$} & 1.1424 & $2.5155^{* *}$ & 10.8123 \\
\hline & 0.624 & 0.028 & 0.233 \\
\hline \multirow[t]{2}{*}{$\mathrm{MGAE}_{\mathrm{t}-1}$} & 21.9767 & 0.8877 & 27.3239 \\
\hline & 0.212 & 0.914 & 0.768 \\
\hline \multirow[t]{2}{*}{$\mathrm{MSAE}_{\mathrm{t}-1}$} & 6.3325 & 16.8094 * & 51.0911 \\
\hline & 0.746 & 0.067 & 0.743 \\
\hline \multirow[t]{2}{*}{ cons } & $0.0239 * \star \star$ & $0.0442^{* \star *}$ & $0.0237^{* * *}$ \\
\hline & 0.000 & 0.000 & 0.007 \\
\hline No. of observations & 611 & 276 & 335 \\
\hline No. of countries & 44 & 20 & 24 \\
\hline Sargan test & 0.000 & 0.000 & . \\
\hline $\mathrm{AR}(1)$ & 0.000 & 0.000 & 0.000 \\
\hline $\mathrm{AR}(2)$ & 0.719 & 0.861 & 0.595 \\
\hline
\end{tabular}

${ }^{1)}$ robust standard errors

Note: MSE...market share effect, SME...structural market effect, MGAE...market growth adaptation effect, MSAE...market stagnation adaptation effect;

instruments used: initial investment, country group dummies. 
Table 3

\section{Effect of export structure on income growth, 1981-1997}

Dependent variable: $\Delta$ In real GDP p.c. at ppp - A-B (one step)

\begin{tabular}{|c|c|c|c|}
\hline & total sample & OECD & non-OECD ${ }^{1)}$ \\
\hline \multirow[t]{2}{*}{$\Delta \operatorname{lnGDP} P_{t-1}$} & $1.0651^{* * *}$ & $0.6641^{* * *}$ & $1.0502^{* * *}$ \\
\hline & 0.000 & 0.000 & 0.000 \\
\hline \multirow[t]{2}{*}{$\Delta \operatorname{lnGDP}_{\mathrm{t}-2}$} & $-0.2429 * * \star$ & $-0.1706^{* * *}$ & $-0.2305^{* * *}$ \\
\hline & 0.000 & 0.000 & 0.000 \\
\hline \multirow[t]{2}{*}{$\Delta \mathrm{InPOP}$} & $-0.3357^{* * *}$ & $-0.5111^{* * *}$ & $-0.5825^{* \star *}$ \\
\hline & 0.000 & 0.000 & 0.003 \\
\hline \multirow[t]{2}{*}{$\Delta \mathrm{INV}$} & 0.0035 & $0.5834^{\star \star \star}$ & -0.0042 \\
\hline & 0.828 & 0.000 & 0.724 \\
\hline \multirow[t]{2}{*}{ InGDP0 } & $-3.12 \mathrm{E}-03^{* * *}$ & $-3.30 \mathrm{E}-03^{* * *}$ & -0.0017 \\
\hline & 0.000 & 0.006 & 0.153 \\
\hline \multirow[t]{2}{*}{ LSCO } & $1.23 \mathrm{E}-04$ ** & 1.63E-05 & 0.0002 \\
\hline & 0.036 & 0.667 & 0.182 \\
\hline \multirow[t]{2}{*}{$\Delta \mathrm{XSH} \_\mathrm{IS} \mathrm{t}-1$} & 0.1174 & -0.0046 & 0.2942 ** \\
\hline & 0.276 & 0.967 & 0.029 \\
\hline \multirow[t]{2}{*}{$\Delta \mathrm{XSH} \_\mathrm{ms} / \mathrm{bc} c_{\mathrm{t}-1}$} & 0.0918 & $0.7142^{* \star *}$ & -0.0656 \\
\hline & 0.707 & 0.001 & 0.790 \\
\hline \multirow[t]{2}{*}{$\Delta \mathrm{XSH} \_\mathrm{ms} / \mathrm{wa}_{\mathrm{t}-1}$} & $0.3419^{* * *}$ & 0.2971 ** & 0.4218 * \\
\hline & 0.000 & 0.016 & 0.064 \\
\hline \multirow[t]{2}{*}{$\Delta \mathrm{XSH} \mathrm{hS}_{\mathrm{t}-1}$} & $-0.1851 *$ & $-0.8381^{* * *}$ & $-0.3315^{* * *}$ \\
\hline & 0.098 & 0.002 & 0.002 \\
\hline \multirow[t]{2}{*}{ cons } & $0.0346^{* * *}$ & $0.0452 * \star \star *$ & 0.0284 ** \\
\hline & 0.000 & 0.000 & 0.011 \\
\hline No. of observations & 610 & 275 & 335 \\
\hline No. of countries & 44 & 20 & 24 \\
\hline Sargan test & 0.000 & 0.000 & . \\
\hline $\operatorname{AR}(1)$ & 0.000 & 0.000 & 0.000 \\
\hline $\operatorname{AR}(2)$ & 0.591 & 0.792 & 0.232 \\
\hline
\end{tabular}

${ }^{1)}$ robust standard errors

Note: $\mathrm{XSH}$ _ls...share of low skill exports in GDP, XSH-ms/bc...share of medium skill, blue collar exports, $\mathrm{XSH} \_\mathrm{ms} / \mathrm{wc}$...share of medium skill white collar exports, XSH_hs...share of high skill exports; see appendix for classfication of industries into skill segments; instruments used: initial investment, country group dummies. 
Table 4

Effect of import structure on income growth, 1981-1997

Dependent variable: $\Delta$ In real GDP p.c. at ppp - A-B (one step)

\begin{tabular}{|c|c|c|c|}
\hline & total sample & OECD & non-OECD ${ }^{1)}$ \\
\hline \multirow[t]{2}{*}{$\Delta \ln G D P_{t-1}$} & $1.0702^{\star \star \star}$ & $0.6901^{* * *}$ & 1.0570 *** \\
\hline & 0.000 & 0.000 & 0.000 \\
\hline \multirow[t]{2}{*}{$\Delta \operatorname{lnGDP}_{\mathrm{t}-2}$} & $-0.2562 * * *$ & $-0.1915^{* * *}$ & $-0.2386^{* * *}$ \\
\hline & 0.000 & 0.000 & 0.000 \\
\hline \multirow[t]{2}{*}{$\Delta \mathrm{lnPOP}$} & $-0.4281^{* \star *}$ & $-0.5185^{* * *}$ & $-0.6421^{* * *}$ \\
\hline & 0.000 & 0.000 & 0.000 \\
\hline \multirow[t]{2}{*}{$\Delta \mathrm{INV}$} & 0.0024 & $0.6010^{* * *}$ & 0.0027 \\
\hline & 0.884 & 0.000 & 0.781 \\
\hline \multirow[t]{2}{*}{ InGDPO } & $-3.17 \mathrm{E}-03^{* \star *}$ & $-2.91 \mathrm{E}-03^{* \star}$ & $-0.0020 * *$ \\
\hline & 0.000 & 0.028 & 0.039 \\
\hline \multirow[t]{2}{*}{ LSCO } & $6.43 E-05$ & 8.84E-06 & 0.0000 \\
\hline & 0.254 & 0.817 & 0.998 \\
\hline \multirow[t]{2}{*}{$\Delta \mathrm{MSH} \_\mathrm{ls} \mathrm{t}_{\mathrm{t}-1}$} & -0.0221 & $0.9197^{* *}$ & -0.1338 \\
\hline & 0.890 & 0.011 & 0.172 \\
\hline \multirow[t]{2}{*}{$\Delta \mathrm{MSH} \_\mathrm{ms} / \mathrm{bc} \mathrm{t}_{\mathrm{t}-1}$} & $-0.3141 *$ & $-0.7372^{* * *}$ & -0.2895 \\
\hline & 0.098 & 0.003 & 0.233 \\
\hline \multirow[t]{2}{*}{$\Delta \mathrm{MSH} \_\mathrm{ms} / \mathrm{wc}_{\mathrm{t}-1}$} & $0.5658^{\star \star \star}$ & 0.3555 & $0.4659^{* * *}$ \\
\hline & 0.000 & 0.158 & 0.009 \\
\hline \multirow[t]{2}{*}{$\Delta \mathrm{MSH} \_\mathrm{hS} \mathrm{t}_{\mathrm{t}-1}$} & -0.1713 & 0.0371 & 0.1286 \\
\hline & 0.506 & 0.910 & 0.684 \\
\hline \multirow[t]{2}{*}{ cons } & $0.0371^{* * *}$ & $0.0418^{* * *}$ & $0.0337^{* * *}$ \\
\hline & 0.000 & 0.001 & 0.000 \\
\hline No. of observations & 610 & 275 & 335 \\
\hline No. of countries & 44 & 20 & 24 \\
\hline Sargan test & 0.000 & 0.000 & . \\
\hline $\mathrm{AR}(1)$ & 0.000 & 0.000 & 0.000 \\
\hline $\operatorname{AR}(2)$ & 0.461 & 0.956 & 0.287 \\
\hline
\end{tabular}

${ }^{1)}$ robust standard errors

Note: MSH_ls...share of low skill imports in GDP, MSH-ms/bc...share of medium skill, blue collar imports, $\mathrm{MSH} \_\mathrm{ms} / \mathrm{wc}$...share of medium skill white collar imports, MSH_hs...share of high skill imports; see appendix for classification of industries into skill segments; instruments used: initial investment, country group dummies. 
Table 5

Effect of trade specialization on income growth, 1981-1997

Dependent variable: $\Delta$ In real GDP p.c. at ppp - A-B (one step)

\begin{tabular}{|c|c|c|c|c|}
\hline & & total sample & OECD & non-OECD \\
\hline \multirow{2}{*}{\multicolumn{2}{|c|}{$\Delta \operatorname{lnGDP}_{\mathrm{t}-1}$}} & $0.8051^{* * *}$ & $0.5073^{* * *}$ & $0.6241^{* * *}$ \\
\hline & & 0.000 & 0.000 & 0.000 \\
\hline \multirow{2}{*}{\multicolumn{2}{|c|}{$\Delta \operatorname{lnGDP} \mathrm{t}_{\mathrm{t}-2}$}} & $-0.2191^{* * *}$ & $-0.2548^{* * *}$ & $-0.1855^{* * *}$ \\
\hline & & 0.000 & 0.000 & 0.000 \\
\hline \multirow{2}{*}{\multicolumn{2}{|c|}{$\Delta \mathrm{InPOP}$}} & $-0.7876^{* * *}$ & $-0.7419^{* * *}$ & $-0.7733^{* * *}$ \\
\hline & & 0.000 & 0.000 & 0.000 \\
\hline \multirow{2}{*}{\multicolumn{2}{|c|}{$\Delta \mathrm{INV}$}} & 0.0033 & 0.7044 *** & 0.0103 \\
\hline & & 0.812 & 0.000 & 0.508 \\
\hline \multirow{2}{*}{\multicolumn{2}{|c|}{ InGDPO }} & $-8.10 \mathrm{E}-03^{* * *}$ & $-4.31 E-05$ & $-1.52 \mathrm{E}-02^{* * *}$ \\
\hline & & 0.000 & 0.995 & 0.000 \\
\hline \multirow{2}{*}{\multicolumn{2}{|c|}{ LSCO }} & $1.91 \mathrm{E}-04$ * & $-2.94 \mathrm{E}-04^{* *}$ & $-3.11 E-05$ \\
\hline & & 0.097 & 0.029 & 0.905 \\
\hline \multicolumn{5}{|c|}{ low skill industries } \\
\hline & \multirow[t]{2}{*}{ RCA311 $1_{t-1}$} & $0.0051^{* \star *}$ & 0.0009 & $0.0063^{* * *}$ \\
\hline & & 0.000 & 0.677 & 0.007 \\
\hline & \multirow[t]{2}{*}{$\mathrm{RCA}_{313} \mathrm{t}_{\mathrm{-}}$} & -0.0014 & 0.0012 & 0.0060 ** \\
\hline & & 0.311 & 0.461 & 0.050 \\
\hline & \multirow[t]{2}{*}{$\mathrm{RCA3} 4_{\mathrm{t}-1}$} & $-0.0018^{*}$ & $-0.0062^{* * *}$ & 0.0028 \\
\hline & & 0.095 & 0.000 & 0.270 \\
\hline & \multirow[t]{2}{*}{ RCA321 $1_{t-1}$} & -0.0016 & -0.0053 & -0.0009 \\
\hline & & 0.284 & 0.119 & 0.708 \\
\hline & \multirow[t]{2}{*}{$\mathrm{RCA3}_{2} 2_{\mathrm{t}-1}$} & $-0.0022^{* *}$ & 0.0035 * & -0.0018 \\
\hline & & 0.026 & 0.052 & 0.257 \\
\hline & \multirow[t]{2}{*}{ RCA323 ${ }_{t-1}$} & -0.0003 & -0.0005 & 0.0030 \\
\hline & & 0.833 & 0.820 & 0.152 \\
\hline & \multirow[t]{2}{*}{ RCA324 $t-1$} & 0.0021 & 0.0030 & 0.0011 \\
\hline & & 0.119 & 0.221 & 0.677 \\
\hline & \multirow[t]{2}{*}{$\mathrm{RCA355}_{\mathrm{t}-1}$} & -0.0017 & -0.0050 & -0.0020 \\
\hline & & 0.367 & 0.122 & 0.537 \\
\hline & \multirow[t]{2}{*}{ RCA356 $t-1$} & 0.0031 & -0.0055 & $0.0085^{* * *}$ \\
\hline & & 0.133 & 0.140 & 0.006 \\
\hline & \multirow[t]{2}{*}{$\mathrm{RCA} 361_{\mathrm{t}-1}$} & -0.0001 & 0.0060 * & -0.0019 \\
\hline & & 0.943 & 0.061 & 0.538 \\
\hline & \multirow[t]{2}{*}{$\mathrm{RCA}_{362} \mathrm{t}-1$} & 0.0009 & -0.0002 & 0.0041 \\
\hline & & 0.585 & 0.922 & 0.180 \\
\hline & \multirow[t]{2}{*}{ RCA369 $_{t-1}$} & -0.0026 * & $-0.0094^{* * *}$ & -0.0006 \\
\hline & & 0.068 & 0.000 & 0.805 \\
\hline & \multirow[t]{2}{*}{$\mathrm{RCA} 371_{\mathrm{t}-1}$} & -0.0005 & 0.0032 & -0.0001 \\
\hline & & 0.792 & 0.108 & 0.980 \\
\hline & \multirow[t]{2}{*}{$\mathrm{RCA} 372_{\mathrm{t}-1}$} & 0.0020 * & 0.0017 & 0.0030 \\
\hline & & 0.075 & 0.590 & 0.164 \\
\hline
\end{tabular}

(Table 5 continued) 
Table 5 (continued)

Effect of trade specialization on income growth, 1981-1997

total sample

medium skill- blue collar

$\mathrm{RCA331} 1_{\mathrm{t}-1}$

RCA332 $t-1$

RCA381 1

RCA384

RCA390 $t-1$

medium skill- white collar

RCA341 $\mathrm{t}-1$

RCA342 $t_{t-1}$

RCA351

RCA352 $\mathrm{t}-1$

RCA353 $t-1$

RCA354 t-1

RCA383 $t-1$

RCA385 $\mathrm{t}-1$

high skill industries

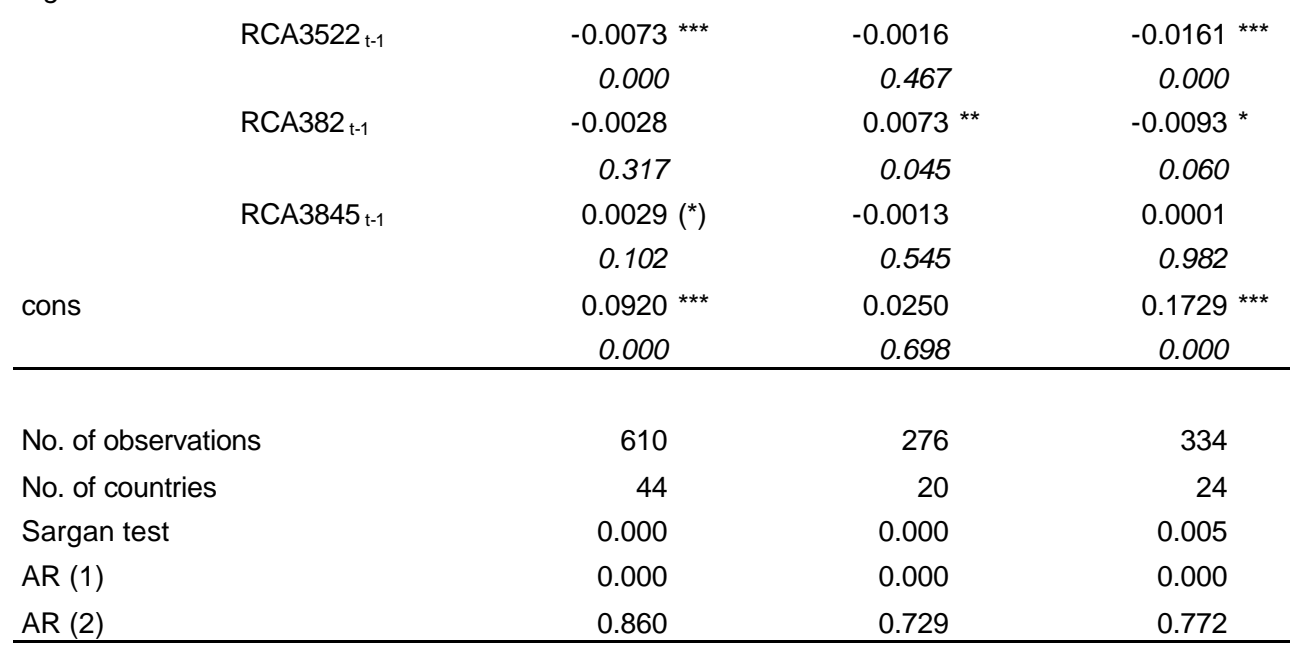

Note: RCA stands for revealed comparative advantage; a listing of industry codes is given in the appendix, instruments used: initial investment, country group dummies.

non-OECD

0.0000
0.982
0.0005
0.882
-0.0055
0.130
0.0016
0.716
0.0075 ***
0.002

$0.0089^{* *}$

0.041

$-0.0057^{* \star *}$

0.007

0.0040

0.326

0.0059 *

0.088

$0.0065^{* * *}$

0.006

$-0.0022$

0.407

0.0250 ***

0.000

0.0016

0.744

$\begin{array}{rrr}0.0009 & 0.0018 & 0.0016 \\ 0.753 & 0.563 & 0.744\end{array}$


